2

\title{
Surface Property Modification of Polylactic Acid by Ion Implantation
}

\author{
Irina Vasenina ${ }^{1,2, *}$, Konstantin Savkin ${ }^{2}$, Olesya Laput ${ }^{2,3}$, Daniil Zuza ${ }^{1}$ and Irina Kurzina ${ }^{1}$ \\ ${ }^{1}$ National Research Tomsk State University, 36 Lenin Ave, Tomsk 634050, Russia \\ ${ }^{2}$ Institute of High Current Electronics, 2/3 Akademichesky Ave., Tomsk 634055, Russia \\ ${ }^{3}$ National Research Tomsk Polytechnic University, 30 Lenin Ave, Tomsk 634050, Russia \\ * Correspondence: ivpuhova@mail.ru
}

\begin{abstract}
We describe our investigations of the surface physicochemical and biological properties of polylactic acid modified by silver, argon and carbon ion implantation to doses of $1 \times 10^{14}, 1 \times 10^{15}$ and $1 \times 10^{16} \mathrm{ion} / \mathrm{cm}^{2}$ at energies of $20 \mathrm{keV}$ (for $\mathrm{C}$ and $\mathrm{Ar}$ ) and $40 \mathrm{keV}$ (for $\mathrm{Ag}$ ). X-ray analysis shows enhancement of coherent scattering regions and lattice constant increase after ion implantation. Secondary electron mass-spectrometry indicates that $\mathrm{Ag}$ concentration in the subsurface layer is less than $80 \%$, but at a depth of $500 \mathrm{~nm}$ does not exceed $1-2 \%$. The silver forms metal particles in the subsurface layer rather than making additional chemical bonds with polymer atoms. Atomic force microscopy reveals that the higher the irradiation dose the larger the surface roughness of the samples. Ag-irradiated samples implanted to a dose of $1 \times 10^{16}$ ions $/ \mathrm{cm}^{2}$ have the highest roughness, $190 \mathrm{~nm}$. Our investigation of the cytotoxicity of two individual donor macrophages shows that Ag-implanted polylactic acid has no negative impact on immune system cells and could be a promising material for biomedical application.
\end{abstract}

Keywords: polylactic acid; ion implantation; surface property modification

\section{Introduction}

Biodegradable materials based on polylactic acid are widely used in biomedicine and tissue engineering because of their biocompatibility and their degradation to lactic acid in biological media [1]. However, the application PLA-based materials for implants are limited by their adhesion characteristics and lack of functional groups for interaction with cellular media.

For improvement of the physicochemical characteristics, surface modification can be used. The use of ion-beam surface modification for the synthesis of new materials, modification of surface structure, formation of composite materials, and for generating predetermined surface patterns, etc., is a well-developed technology. Ion- and electron-beam irradiation of polymers are techniques widely used for polymer treatment due to their environmental friendliness and wide range of treatment conditions. The shallow ion penetration depth can modify the polymer surface functional properties while maintaining the original bulk properties of the material [2]. The chemical and physical processes leading to modification of the structural and physicochemical properties of polymer materials have been studied.

It is known that ion irradiation techniques can significantly modify the chemical and functional properties of materials. Ion irradiation leads to scission of molecular chains and emission of volatile products from the surface, and increased implantation dose leads to lower density of the implanted region [3]. Polymer chain scission accompanied by surface oxidation processes and new functional 
group formation, which contribute to the material hydrophilicity, occurs as a consequence of ion implantation [4]. Ion implantation of negative carbon ions has been found [5] to promote nerve-cell attachment and nerve line regeneration. It has been shown [6] that plasma treatment of polylactic acid surfaces causes surface roughness and an increase in contact angle, and, in turn, the increased roughness was found to improve PLA biocompatibility [7]. Electron beam treatment of PLA surfaces has been shown to cause polymer chain length transformation, with the molecular weight and degree of crystallinity decreasing proportionally to the exposure dose increase [8,9].

Plasma treatment is often used as a pre-treatment technology and for surface activation followed by distinct coating processes, e.g. chemical modification by grafting of organic functional groups [10] and deposition of plasma polymerized acrylic acid on a PLA surface [11]. It has been found that these hybrid methods of surface modification promote improved wettability, increased surface roughness, and changes in chemical composition. Bastekova and co-workers confirm [10] that their approach allows spatially distributed properties, for instance, hydrophilic and bio-adhesive on one side and hydrophobic and bio-repulsive on the other side, as is highly desirable for medical (implants) application. In contrast, Zhao et al [11], in their method of PLA modification, focus on the food packaging industry to economically and effectively protect food quality by use of an optimal combination of different gases. Morent et al have investigated the aging behavior of plasma-treated polylactic acid [12]. Contact angle decrease and XPS data reveal that the plasma discharge gas (air, nitrogen, argon or helium) has a significant influence on the ageing behavior of PLA foils. This influence can be explained by the different degree of cross-linking of the plasma-treated surfaces: helium and argon plasma-treated PLA films have a high degree of cross-linking, which limits polymer chain mobility and as a result reduces the ageing process. In contrast, the ageing behavior of air and nitrogen plasma-treated films is more pronounced due to their low degree of cross-linking. Other group have studied the aging of plasma-treated PLA, and the maximum storage time of PLA treated with atmospheric plasma for which the sample retains its good adhesion properties has been found to be lower than three days under normal atmospheric conditions [13]. The hydrophobicity and water absorption time can be enhanced by SF6 plasma treatment [14]. The authors explain this by the incorporation of fluorinated functional groups in the surface of the PLA film.

Chemical modification of PLA microspheres by aminolysis and grafting-coating [15] demonstrates the possibility to create material with the ability to support the attachment and proliferation of chondrocytes. These results show that collagen-coated PLA microspheres are a promising candidate for cell microcarriers. Another PLA surface modification technique is excimer laser treatment, described in [16], where the surface wettability, morphology and roughness changes as well as mass loss by ablation are investigated. It is revealed that decreased contact angle is associated with increased number of laser pulses. The excimer laser has a strong effect on polymer ablation; the mass loss is strongly dependent on the laser fluence and number of pulses.

Our literature review shows that ion- and electron-beam treatment of PLA leads to a reduction in molecular weight and degree of crystallinity, increased hydrophilicity, and bioresorption. However, the mechanisms occurring in PLA under ion beam irradiation have not been investigated; there are no data of PLA surface properties after Ag, C, or Ar ion implantation. Thus exploration of the effects of various kinds of ions and ion implantation conditions on PLA functional characteristics is of interest. The aim of the work described here was to study the influence of implantation of 
various ion kinds (silver, argon, carbon) at exposure doses of $1 \times 10^{14}, 1 \times 10^{15}$, and $1 \times 10^{16}$ ions $/ \mathrm{cm}^{2}$ on the surface physicochemical, functional and biological properties of PLA.

\section{Materials and Methods}

\subsection{Preparation of PLA samples}

PLA samples were prepared by dissolving polylactic acid ([-OCH(CH3)-CO-]n) with molecular weight of $250000 \mathrm{~g} / \mathrm{mol}$ in chloroform at room temperature in a 7\% solution [17]. The solvent was then removed by drying at room temperature in a Petri dish to form material with thickness $\sim 1 \mathrm{~mm}$, then the PLA plates were cut into samples with area $10 \times 10 \mathrm{~mm}^{2}$.

\subsection{Ion implantation}

Ion implantation was done using a facility incorporating our Mevva-V.Ru vacuum arc ion source [18]. This implantation facility operates in a repetitively pulsed mode with repetition rate 10

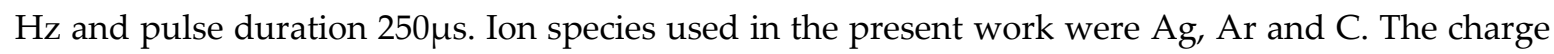
state distributions of the ion beams were measured by a time-of-flight mass-to-charge spectrometer [19]. In this kind of ion source, gaseous ions are singly ionized and hence we used Ar+ ions. Metal ions are in general multiply ionized; for carbon the charge state of the extracted ion beam is singly ionized $\mathrm{C}^{+}$, while for silver the mean charge state of the extracted beam is 2+.Thus the implantation beams include $\mathrm{Ag}^{2+}, \mathrm{Ar}^{+}$and $\mathrm{C}^{+}$ions. Since the ion source extraction voltage was always $20 \mathrm{kV}$, the ion beam energies were $40 \mathrm{keV}, 20 \mathrm{keV}$ and $20 \mathrm{keV}$, respectively. For $\mathrm{Ar}^{+}$ion generation we used the same ion source but somewhat modified to form a hollow cathode glow discharge mode [20]. Implantations were carried out to accumulated doses of $1 \times 10^{14}, 1 \times 10^{15}$, and $1 \times 10^{16} \mathrm{ions} / \mathrm{cm}^{2}$. The implantation dose rate and average beam power density at the PLA target were adjusted by the ion beam current and pulse repetition rate, and were $1 \times 10^{11} \mathrm{ions} /\left(\mathrm{cm}^{2} \cdot \mathrm{sec}\right)$ and $0.5 \mathrm{~mW} / \mathrm{cm}^{2}$, respectively. The samples were mounted on a water-cooled target holder whose temperature did not exceed $20^{\circ} \mathrm{C}$. A working pressure of $1 \times 10^{-6}$ Torr was maintained by an oil-free high-vacuum cryogenic pump.

\subsection{Characterization techniques}

Phase composition was investigated using an XRD-7000S (Shimadzu) X-ray diffractometer with a $\mathrm{K}_{\alpha} \mathrm{Cu}$ source. A Perkin-Elmer PHI 6300 ion microprobe secondary ion mass spectrometer was used to evaluate ion distribution profiles. $\mathrm{Cs}^{+}$ions with energy $7 \mathrm{keV}$ and $\mathrm{O}^{+}$ions with energy 5 $\mathrm{keV}$ were used for etching the PLA samples. The sample surface was scanned by a focused primary ion bean over an area of $500 \times 500 \mu \mathrm{m}^{2}$.

Surface morphology was studied by atomic force microscopy (AFM) using an NTEGRA Aura scanning probe microscope in tapping mode. A NT-MDT Spectrum Instruments probe NSG01 with resonant frequency $150 \mathrm{kHz}$ and force constant $5.1 \mathrm{~N} / \mathrm{m}$ was scanned over an area of $50 \times 50 \mu \mathrm{m}$; Gwyddion software was used for analysis. After survey, an $X Y$ autoplane correction was performed. Structural analysis was carried out by scanning electron microscopy using a Quanta 200 3D dual-beam scanning electron microscope (SEM) and focused ion beam (FIB) instrument. Magnifications from 1000 to 15000 were used at accelerating voltage of $20 \mathrm{kV}$, with spot size 2-3 nm. Before the SEM study, the samples were coated with a conducting graphite film of $2-5 \mathrm{~nm}$ thickness by magnetron sputtering to alleviate charge build-up on the surface. 
124

125

126

127

128

129

130

131

132

133

134

135

136

137

138

139

140

141

142

143

144

145

146

147

148

149

Cellular investigation was performed to primary evaluation of cytotoxicity. Human immune system cell (monocyte) reaction was investigated by cell-mediated immune response to monocytes CD14+. Monocytes from the blood of individual donors were separated [21], and cells were cultured in the presence of the samples for 6 days at $37^{\circ} \mathrm{C}$ in an atmosphere of $7.5 \% \mathrm{CO}_{2}$. Cells cultured without samples were used as controls. The viability of cells was assessed after cultivation (evaluation of metabolic activity of cells).

\section{Results}

\subsection{Elemental and phase composition}

The XPS analysis results reported in [22] reveal that silver after ion implantation does not form new chemical bonds with substrate atoms, but rather, forms metal nanoclusters in the PLA subsurface layer. A two-fold decrease of the PLA molecular weight was shown to occur after ion implantation, regardless of the ion species [23].

There are two dominant peaks, typical for $L$-lactic acid isomers, corresponding to angles $2 \Theta \approx$ $19.1^{\circ}$ and $16.9^{\circ}$ and crystallographic plane with index [201] and [110], respectively, in XRD images of the initial and implanted PLA samples, as shown in Fig. 1. In addition, there is a low-grade peak at $2 \Theta \approx 29.5^{\circ}$, specific to the [020] plane, in the initial and C-implanted samples but not in other samples. A decrease of peak intensity occurs depending on the implanted ion species, associated with the PLA crystallographic parameter alteration (interplane spacing, coherent-scattering region; see Table 1) during the implantation process; the degree of intensity decrease can be arranged in the following order: $\mathrm{Ag} \rightarrow \mathrm{Ar} \rightarrow \mathrm{C}$.

Table 1. Crystallographic parameters of PLA

\begin{tabular}{ccc}
\hline $\begin{array}{c}\text { Implanted } \\
\text { ions }\end{array}$ & $\begin{array}{c}\text { Coherent-scattering } \\
\text { region, } \mathbf{n m}\end{array}$ & $\begin{array}{c}\text { Interplanar } \\
\text { distance, } \AA\end{array}$ \\
\hline initial & 11 & 5.252 \\
$\mathrm{Ag}$ & 14 & 5.296 \\
$\mathrm{Ar}$ & 12 & 5.277 \\
$\mathrm{C}$ & 10 & 5.271 \\
\hline
\end{tabular}

It was found that silver ion implantation results in XRD peak narrowing and line displacement relative to the initial sample, and hence the degree of crystallinity of the material increases. Carbon ion implantation, on the contrary, leads to peak broadening, caused by an increase of crystalline phase distribution heterogeneity and crystallite size. Argon ion implantation of PLA surface does not lead to a change in the coherent-scattering region relative to the initial state.

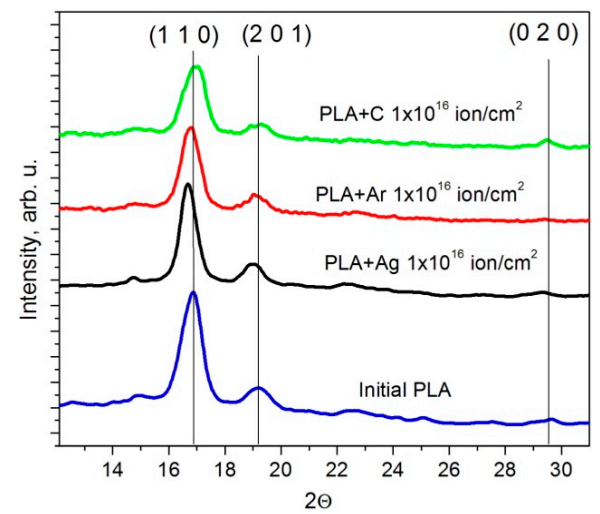

Figure 1. Diffraction patterns of initial and Ag-, Ar-, C- implanted PLA samples 
152

153

154

155

156

157

158

159

160

161

162

163

164

165

166

167

168

169

170

171

172

173

174

Figure 1 shows the peak with index [110], corresponding to $2 \Theta \approx 16.9^{\circ}$ in the initial sample, is shifted to $2 \Theta \approx 16.7^{\circ}$ when it is implanted with $\mathrm{Ag}$ ions, caused by interplanar distance alteration because of defects of the crystal lattice which are formed by silver particles localized in the surface sample (Table 1).

The atomic distribution spectrum of $1 \times 10^{16} \mathrm{ion} / \mathrm{cm}^{2}$ Ag-implanted PLA samples, from the surface to $600 \mathrm{~nm}$ depth, is shown in Figure 2. Secondary ion mass spectrometry data reveal that the maximum Ag concentration in the subsurface layers is up to 80 rel.\%. At a depth of more than 500 $\mathrm{nm}$, the Ag concentration does not exceed 1-2 rel.\%. Moreover, there are two peak of Ag: the first is at $100 \mathrm{~nm}$ depth, where the maximum concentration is $80 \mathrm{rel} \%$; the second one is at $180 \mathrm{~nm}$ depth, where the Ag concentration is $50 \mathrm{rel} . \%$. There are $40 \mathrm{rel} . \%$ of silver and $40 \mathrm{rel} . \%$ of carbon on top of the PLA surface layer. The penetration of silver ions into the polymer is carried out as follows: some ions settle on the surface and lose their charge, aggregating into metallic nanoparticles, and other ions are distributed in a more-or-less Gaussian distribution over the depth of the surface layer. The effect of ion implantation is observed to a depth of up to $600 \mathrm{~nm}$.

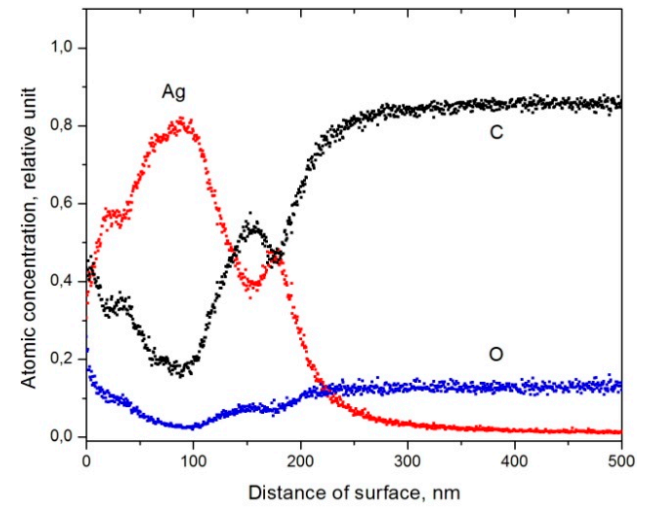

Figure 2. Atomic distribution in the subsurface layer of PLA

According to SIMS data for Ar- and C-implanted PLA, a uniform distribution of implanted ions over the depth of the implantion is observed. The calculated projected range of ions is $200-250$ for the given ion energies.

\subsection{Morphological characteristics}

The SEM image shown in Fig. 3(a) reveals metal nanoclusters with average size $130 \mathrm{~nm}$; the particle size distribution is shown in Fig. 3(b).

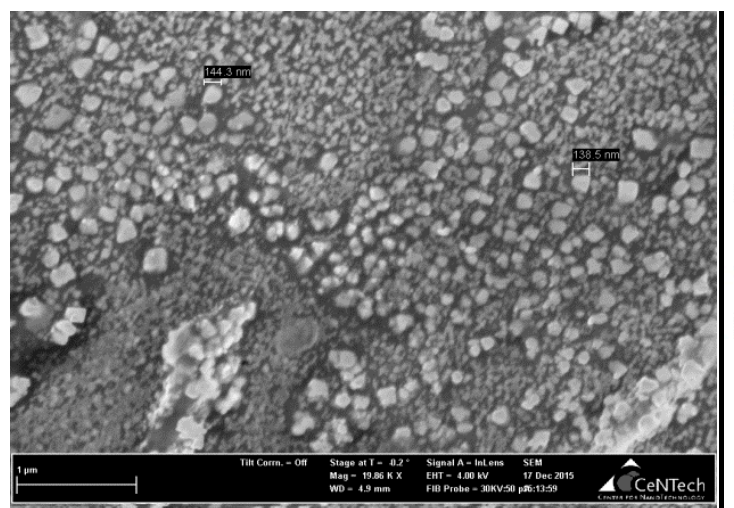

(a)

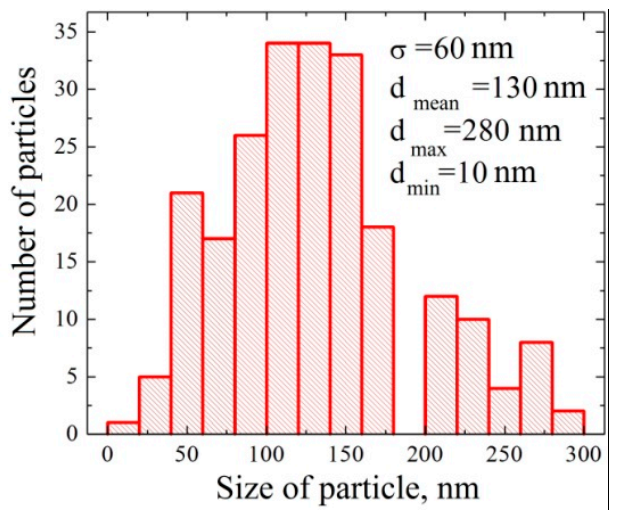

(b)

Figure 3. (a) SEM image of $1 \times 10^{16} \mathrm{ion} / \mathrm{cm}^{2}$ Ag-implanted PLA; (b) Particle size distribution 
177

178

179

180

181

182

183

184

185

\begin{tabular}{ccccc}
\hline Sample & Initial & Ag-implanted & Ar-implanted & C-implanted \\
\hline Roughness ( $\left.\mathbf{R}_{\mathbf{a}}\right), \mathbf{n m}$ & 126 & 190 & 159 & 161 \\
\hline
\end{tabular}

186

187

188

189

In Figure 4 the AFM results of initial and $1 \times 10^{16} \mathrm{ion} / \mathrm{cm}^{2} \mathrm{Ag}-$, Ar-, C-treated PLA samples are shown. Significant morphology modification was found to occur following ion implantation, dependent on the implanted ion species. The highest surface roughness is observed in Ag-implanted samples, and is due to formation of metal nanoparticles (Table 2). Implantation of Ar and C ions into the PLA surface causes lesser topography changes, probably due to their inertness and affinity for the substrate material, respectively. The roughness increase can promote cell adsorption improvement. When carbon ions are implanted, the formation of nanoclusters, which are located in the near-surface layer, is possible.

Table 2. Surface roughness of initial and $1 \times 10^{16} \mathrm{ion} / \mathrm{cm}^{2} \mathrm{Ag}-$, Ar-, C-implanted PLA samples

The TEM images shown in Figure 5 reveal that metal nanoparticles with average size of 2-3 nm are formed in the surface when PLA is implanted with Ag. On the other hand, cavitation with average pore size $10 \mathrm{~nm}$ is observed for the Ar- and C-implanted samples. We assume that the pores are filled with atomic argon and carbon, respectively.

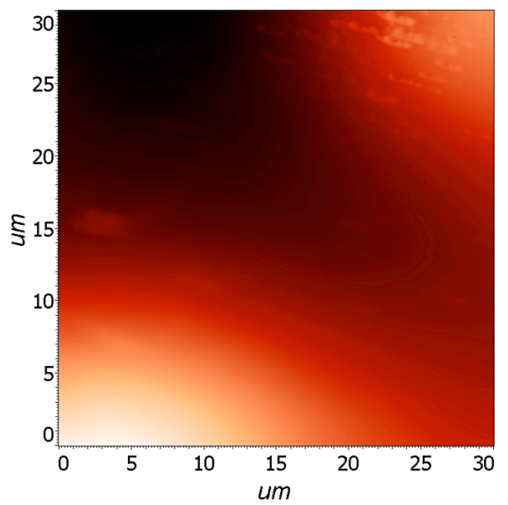

(a)

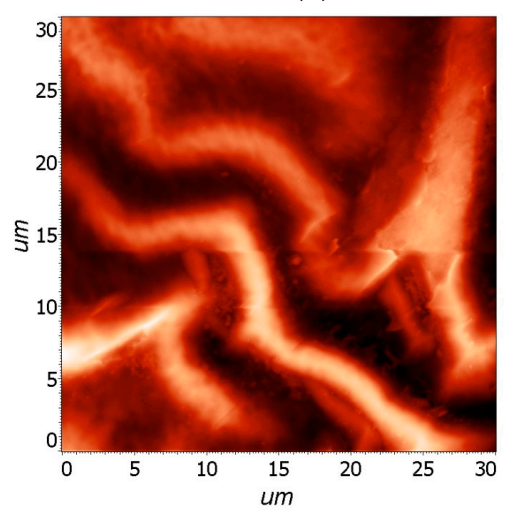

(c)
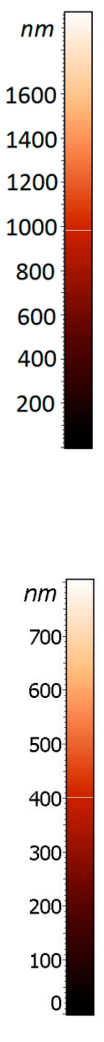

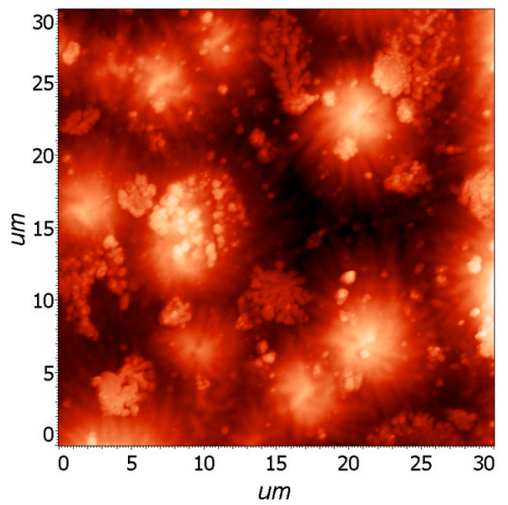

(b)

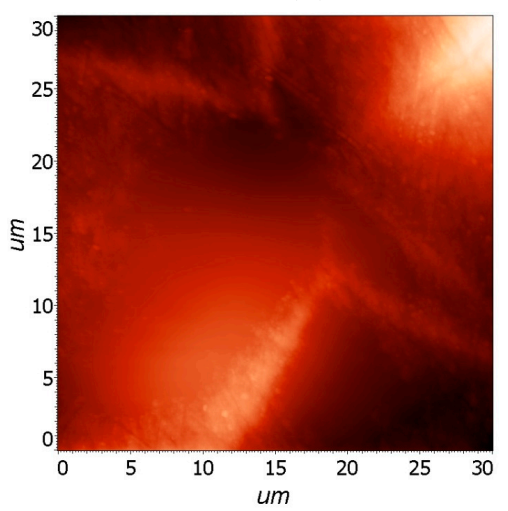

(d)
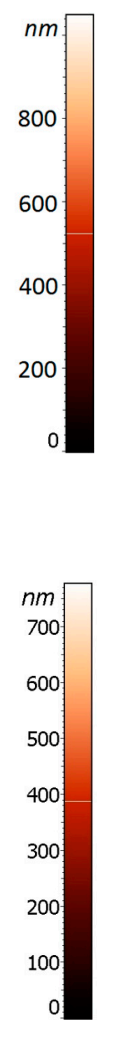

Figure 4. AFM images of PLA samples: a) initial; b) Ag-; c) Ar-; d) C-implanted with dose of $1 \times 10^{16}$ ions $/ \mathrm{cm}^{2}$ 


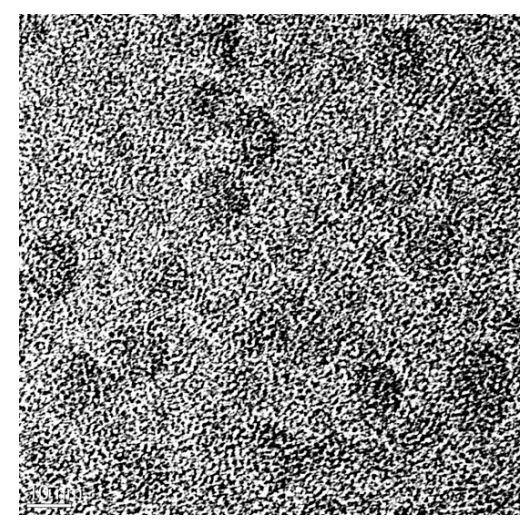

(a)

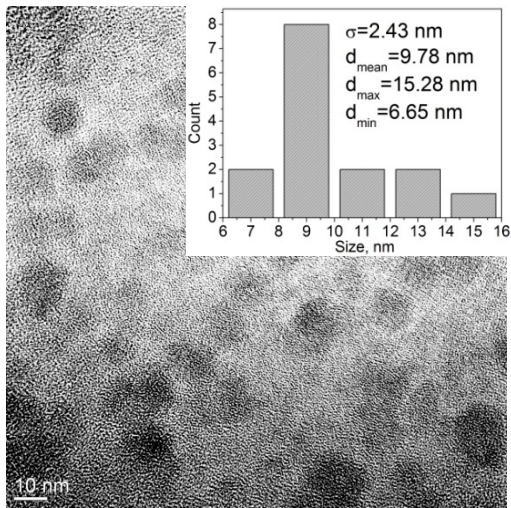

(c)

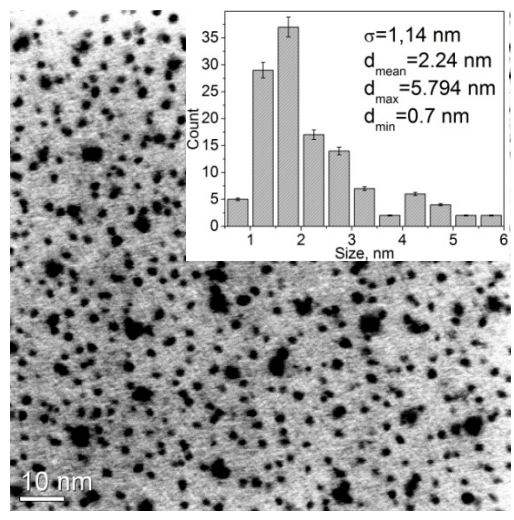

(b)

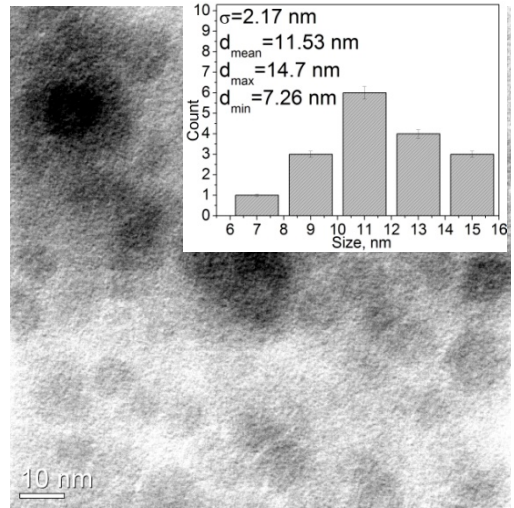

(d)

Figure 5. TEM images of PLA samples: a) initial; b) Ag-; c) Ar-; d) C-implanted with dose of $1 \times 10^{16}$ ions $/ \mathrm{cm}^{2}$

\subsection{Biocompatibility of PLA}

The primary evaluation of cytotocxicity with macrophage from two individual donors reveals that both initial and $1 \times 10^{16}$ ions $/ \mathrm{cm}^{2} \mathrm{Ag}$-implanted PLA samples benefit immune system cells (Fig. 6). The macrophage level after 6 days of culturing with PLA samples remains approximately the same as the control sample (pure glass). When cells are interacted with the Ag-implanted PLA sample, though, the cell survivability decreases relative to the control and initial PLA sample, but the cells remain alive. We found that the amount of living immune system cells is slightly diminished in the presence of Ag on the PLA surface; however there is no sharp rejection of implanted material by biological medium.

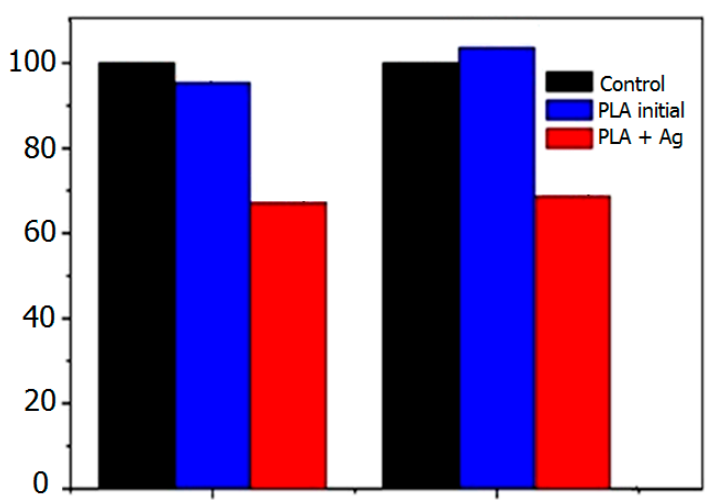

Donor 1
Donor 2

Figure 6. Cytotoxocity of PLA in vitro 


\section{Conclusion}

The effect of $1 \times 10^{14}, 1 \times 10^{15}$, and $1 \times 10^{16} \mathrm{ion} / \mathrm{cm}^{2} \mathrm{Ag}$, $\mathrm{Ar}$, and $\mathrm{C}$ ion implantation on PLA surface physicochemical and biological properties was investigated. We find that ion implantation influences the elemental compound and structural-phase composition. Thus implanted silver does not form new chemical bonds with polymer molecules but aggregates as metal nanoparticles on the PLA surface. It was established that the PLA molecular weight decreases by a factor of two after ion implantation regardless of the ion species used. The surface properties of the polymer are modified by energetic ion impact. XRD analysis revealed that the coherent-scattering region and interplanar distance of PLA are enhanced due to ion bombardment and crystallographic parameter alteration. According to SIMS, the Ag concentration in the subsurface layer is 80 rel.\%, and for depth greater than $500 \mathrm{~nm}$ does not exceed 1-2 rel.\%. It was found that the surface roughness increases with implantation dose; 1 x 1016 $\mathrm{ion} / \mathrm{cm}^{2}$ Ag-implanted samples have the greatest roughness of $190 \mathrm{~nm}$. Evaluation of cytotocxicity with the macrophage of two individual donors was carried out and it was revealed that ion beam treated material does not negatively influence immune system cells and could thus be a promising material for biomedical application.

Acknowledgments: This work was supported by the Russian Foundation for Basic Research (RFBR) project \#15-08-05496, and by the Tomsk State University competitiveness improvement program (project \# 8.2.06.2017). Special thanks are extended to the Center for Collective Use NR TSU, the Research Centre "Nanomaterials and Nanotechnologies" NR TPU and personally to A.V. Chernyavsky and M.P. Kalashnikov their assistance and support.

Author Contributions: Irina Kurzina is the leader of the group; she conceived and designed the experiments. Konstantin Savkin performed the ion implantation of polylactic acid. Irina Vasenina and Olesya Laput investigated the surface property of the modified samples. Irina Vasenina, Olesya Laput and Daniil Zuza analyzed the data. Irina Vasenina wrote the paper.

Conflicts of Interest: The authors declare no conflict of interest. The founding sponsors had no role in the design of the study; in the collection, analyses, or interpretation of data; in the writing of the manuscript, and in the decision to publish the results.

\section{References:}

1. Gilding D.K., Reed A.M. Biodegradable polymers for use in surgery - Polyglycolic-poly(acetic acid) homopolymers and copolymers: Part 1. Polymer 1979, 20, 1459-1464, DOI: 10.1016/0032-3861(79)90009-0.

2. Kwon H.-J., Jung C.-H., Kim D.-K., Lim Y.-M., Kim H.-K., Nho Y.-C., Choi J.-H., Biocompatibility improvement of polytetrafluoroethylene by ion implantation. Journal of the Korean Physical Society 2008, 52, 3, 819-823, DOI: 10.3938/jkps.52.819.

3. Saito F., Yotoriyama T., Nishiyama I., Suzuki Y., Goto A., Nagashima Y., Hyodo T. Characterization of ion-irradiated poly-L-lactic acid using nano-cutting. Phys. Chem. Chem. Phys. 2014, 16, 26991-26996, DOI: 10.1039/c4cp02763a.

4. Sokullu-Urkac E., Oztarhan A., Tihminlioglu F., Nikolaev A., Brown I. Oxidation Behavior of C- and Au-Ion-Implanted Biodegradable Polymers, IEEE Transactions on Plasma Science 2012, 40, 3, 863-869, DOI: 10.1109/TPS.2011.2179677. 
5 Ishikawa J., Tsuji H., Sato H., Gotoh Y. Ion implantation of negative ions for cell growth manipulation and nervous system repair, Surface $\mathcal{E}$ Coatings Technology 2007, 201, 8083-8090, DOI: 10.1016/j.surfcoat.2006.01.073.

6. Song A. Y., Oh Y. A., Roh S. H., Kim J. H., Min S. C. Cold oxygen plasma treatments for the improvement of the physicochemical and biodegradable properties of polylactic acid films for food packaging. Journal of Food Science 2016, 81, 1, 86-96, DOI: 10.1111/1750-3841.13172.

7. Tverdokhlebov S.I., Bolbasov E.N., Shesterikov E.V., Antonova L.V., Golovkin A.S., Matveeva V.G., Petlin D.G., Anissimov Y.G. Modification of polylactic acid surface using RF plasma discharge with sputter deposition of a hydroxyapatite target for increased biocompatibility. Applied Surface Science 2014, 329, 1-18, DOI:10.1016/j.apsusc.2014.12.127.

8. Leonard D. J., Pick L. T., Farrar D.F. The modification of PLA and PLGA using Electron-beam radiation. Journal of Biomedical Materials Research Part A 2008, 89A, 3, 567-574, DOI: 10.1002/jbm.a.31998.

9. Loo J. S. C., Ooi C. P., Boey F. Y. C. Degradation of poly (lactide-coglycolide) (PLGA) and poly(-lactide) (PLA) by electron beam radiation. Biomaterials 2005, 26, 1359-1367, DOI: 10.1016/j.biomaterials.2004.05.001.

10. Bastekova K., Guselnikova O., Postnikov P., Elashnikov R., Kunes M., Kolska Z., Svorcík V., Lyutakov O. Spatially selective modification of PLLA surface: From hyhydrophilic or to repellent, Applied Surface Science 2017, 397, 226-234, DOI: 10.1016/j.apsusc.2016.11.062.

11. Zhao Y., Fina A., Venturello A., Geobaldo F. Effects of gas atmospheres on poly(lactic acid) film in acrylic acid plasma treatment. Applied Surface Science 2013, 283, 181-187, DOI: 10.1016/j.apsusc.2013.06.078.

12. Morent R., De Geyter N., Trentesaux M., Gengembre L., Dubruel P., Leys C., Payen E. Influence of discharge atmosphere on the ageing behaviour of plasma-treated polylactic acid. Plasma Chem Plasma Process 2010, 30, 525-536, DOI 10.1007/s11090-010-9233-8.

13. Jorda-Vilaplana A., Sanchez-Nacher L., García-Sanoguera D., Carbonell A., Ferri J. M. Effects of aging on the adhesive properties of poly(lactic acid) by atmospheric air plasma treatment. Journal of Applied Polymer Science 2016, 133, 11, 43040, DOI: 10.1002/APP.43040.

14. Chaiwong C., Rachtanapun P., Wongchaiya P., Auras R., Boonyawan D. Effect of plasma treatment on hydrophobicity and barrier property of polylactic acid, Surface $\mathcal{E}$ Coatings Technology 2010, 204, 2933-2939, DOI: 10.1016/j.surfcoat.2010.02.048.

15. Hong Y., Gao C., Xie Y., Gong Y., Shen J., Collagen-coated polylactide microspheres as chondrocyte microcarriers. Biomaterials 2005, 26, 6305-6313, DOI: 10.1016/j.biomaterials.2005.03.038.

16. Slepicka P., Michaljanicová I., Sajdl P., Fitl P., Svorcík V. Surface ablation of PLLA induced by KrF excimer laser. Applied Surface Science 2013, 283, 438-444, DOI: 10.1016/j.apsusc.2013.06.127.

17. Botvin V.V., Shapovalova E.G., Zenkova E.V., Pozdnyakov M.A. Synthesis of glycolic and lactic acid oligomers. Proceedings of the X International Conference of Students and Young Scientists "Prospects of Fundamental Sciences Development 2013, 266-268, in Russian.

18. Nikolaev A.G., Oks E.M., Savkin K.P., Yushkov G.Yu., Brown I.G. Upgraded vacuum arc ion source for metal ion implantation. Review of Scientific Instruments 2012, 83, 2 02A501, DOI: 10.1063/1.3655529.

19. Gushenets V.I., Nikolaev A.G., Oks E.M., Vintizenko L.G., Yushkov G.Yu. Simple and inexpensive time-of-flight charge-to-mass analyzer for ion beam source characterization. Review of scientific instruments 2006, 77, 063301, DOI: 10.1063/1.2206778.

20. Yushkov G.Yu., MacGill R.A., Brown I.G., Mevva ion source operated in purely gaseous mode, Review of Scientific Instruments 2004, 75, 5, 1582-1584, DOI: 10.1063/1.1691474. 
21. Gratchev A., Kzhyshkowska J., Köthe K., Muller-Molinet I., Kannookadan S., Utikal J., Goerdt S. M1 and M2 can be re-polarized by Th2 or Th1 cytokines respectively, and respond to exogenous danger signals. Immunobiology 2006, 211, 473-486, DOI: 10.1016/j.imbio.2006.05.017.

22. Kurzina I.A., Pukhova I.V., Botvin V.V., Davydova D.V., Filimoshkin A.G., Savkin K.P., Oks E.M. New materials based on polylactide modified with silver and carbon ions. Proceedings of the 5th International Scientific Conference «New Operational Technologies» AIP Conf. Proc. 2015, 1688, 030033, DOI: 10.1063/1.4936028.

23. Pukhova I.V., Savkin K.P., Laput O.A., Lytkina D.N., Botvin V.V., Medovnik A.V., Kurzina I.A., Effect of ion-plasma and electron-beam treatment on surface physicochemical properties of polylactic acid. Applied Surface Science 2017, 422, 856-862, DOI: 10.1016/j.apsusc.2017.06.112. 